\title{
A INFLUÊNCIA DA INDÚSTRIA CULTURAL NO ENSINO DE MÚSICA NA ESCOLA
}

João Wesley Zengo, Patrícia Mertzig Gonçalves de Oliveira

Universidade do Oeste Paulista - UNOESTE, Presidente Prudente -SP. E-mail: jao w@hotmail.com

\section{RESUMO}

O presente artigo tem como objetivo identificar, apresentar e analisar como a Indústria Cultural influencia na formação do gosto musical dos alunos a ponto de dificultar alguns conteúdos e metodologias em educação musical no espaço escolar. Para tanto iniciaremos definindo o termo Indústria Cultural a partir da definição de W. Adorno e outros autores da chamada Escola de Frankfurt. Na sequência será abordada a função da música no espaço escolar a partir da leitura de documentos oficias como os Parâmetros Curriculares Nacionais de Arte para o Ensino Médio (2000) e o Currículo Nacional do Ensino Básico - competências Essenciais (2011). Para finalizar será analisado como a Indústria Cultural pode ser abordada em sala de aula e como esta pode se tornar um importante elemento de discussão contribuindo na formação crítica desses alunos.

Palavras-chave: Indústria Cultural; Escola de Frankfurt; Educação Musical; Documentos Oficiais.

\section{THE INFLUENCE OF CULTURAL INDUSTRY IN THE MUSIC TEACHING IN SCHOOL}

\begin{abstract}
This article aims to identify, present and analyze how the Cultural Industry influence in shaping the musical tastes of students to the point of hindering some content and methodologies in music education at school. For both we start by defining the term Cultural Industries from the definition of W. Adorno and other authors by Frankfurt School. Will be addressed in the sequel the function of music in school by reading official documents such as the National Curriculum Parameters of Art for High School (2000) and the National Curriculum of Basic Education - Essential skills (2011). To end will be analyzed as the cultural industry can be approached in the classroom and how this can become an important element contributing to the critical discussion of students in training.

Keywords: Cultural Industry; Frankfurt School; Music Education; Official Documents.
\end{abstract}




\section{INTRODUÇÃO}

Segundo Koellreutter (1997, p. 37).

Um tipo específico de sociedade condiciona um tipo específico de arte, porque a função da arte varia de acordo com as intenções e as necessidades da sociedade, porque o sistema social, o sistema de convivência inter-humana é governado pelo esquema de condições econômicas; porque é das necessidades objetivas da sociedade que resulta a função da arte.

Com esse pensamento do grande educador musical e expoente da música contemporânea no Brasil, podemos observar que a função da arte é, para o referido autor, atender as necessidades de uma sociedade. Aqui, especificamente, Koellreutter escreve sobre a inserção da música contemporânea no ensino de música nas escolas, mas podemos ampliar essa ideia para refletir sobre qual a função social da música na escola e quais as dificuldades encontradas por alunos e professores ao abordarem a música em sala de aula.

Nesse sentido o presente artigo tem como objetivo identificar, apresentar e analisar como a Indústria Cultural ou ainda, a cultura de massa, influencia na formação do gosto musical dos alunos a ponto de dificultar alguns conteúdos e metodologias em educação musical no espaço escolar. Para tanto iniciaremos definindo o termo Indústria Cultural a partir da definição de W. Adorno e outros autores da chamada Escola de Frankfurt. Na sequencia será abordada a função da música no espaço escolar e como a Indústria Cultural interfere na compreensão e discussão dos conteúdos musicais. Para finalizar será analisado como a Indústria Cultural pode ser abordada no sentido de compreender sua efetiva ação no gosto musical dos alunos e como esta pode se tornar um importante elemento de discussão contribuindo na formação crítica desses alunos.

Destarte o artigo apresenta abordagem teórica por meio de principais referencias na área da Indústria Cultural. Apresenta ainda a função da música no espaço escolar apresentada nos documentos oficiais tais como os PCN de Arte para o Ensino Médio (2000) e o Currículo Nacional do Ensino Básico - competências Essenciais (2011). Para finalizar, discute a Indústria Cultural como conteúdo formador de opinião crítica em relação à produção artística da sociedade atual levando o aluno a se posicionar criticamente.

\section{METODOLOGIA}

A Indústria Cultural surgiu no começo do século XX com a Revolução Industrial e abrange toda forma de se lucrar com a arte, independente de sua linguagem. Indústria Cultural foi o termo que foi criado por Theodor W. Adorno e Max Horkheimer em 1942 no ensaio Dialética do 
Esclarecimento publicado no pós-guerra. Expoentes da Escola de Frankfurt, o termo vem ao encontro do sistema capitalista que visa somente o lucro e enxerga toda a população como consumidores de seus produtos e não como pessoas.

O cinema e o rádio não tem mais necessidade de serem empacotados como arte. A verdade de que nada são além de negócios lhes serve de ideologia. Esta deverá legitimar o lixo que produzem de propósito. O cinema e o rádio se autodefinem como indústrias, e as cifras publicadas dos rendimentos de seus diretores-gerais tiram qualquer dúvida sobre a necessidade social de seus produtos. (ADORNO, 2002, p.8).

No Brasil, especificamente, podemos observar uma manipulação de gosto disseminada pelas mídias sociais que promovem programas e artistas pondo em julgamento a música e a performance musical. Aqui já observamos a total influência da Indústria Cultural nas músicas, pois esse formato de programa agrada uma grande parte da população que o consome ferozmente e utiliza-se somente de músicas oriundas da indústria com a pretensão de obter audiência e lucro.

0 capitalismo concorrencial, presente nos inícios da era burguesa, transformouse cada vez mais em monopolista. Entretanto, devido ao fato de que a indústria cultural necessita o tempo todo prestar atenção às necessidades genéricas de seus consumidores por meio de um olhar estatístico aguçado, o espírito inicial do liberalismo ainda sobrevive em alguma medida nesse âmbito, pois necessita sempre de talentos capazes de sintonizar as mercadorias com as tendências de recepção. (DUARTE, 2004, p. 194).

Com isso muitas pessoas se veem necessitadas de coisas fúteis para se sentirem inseridas na sociedade. Observamos que os alunos somente escutam as músicas que os jogadores de futebol mais famosos escutam e disseminam nas comemorações dos gols que fazem trazendo, inclusive, essas informações ao ambiente escolar. E como proceder com o ensino de música frente a um bloqueio e um preconceito musical por parte desses alunos que, influenciados pela mídia, tecem comentários como somente as músicas que fazem sucesso são boas? E quais os critérios para essa classificação? Musicalmente falando, observamos que as músicas de massa, outra terminologia adotada pela Escola de Frankfurt, possuem não só letras simples de fácil compreensão e com um refrão marcante, mas também estruturas melódicas, rítmicas e harmônicas de igual simplicidade que empobrecem as possibilidades musicais e limitam a criatividade.

É preciso então compreender o meio social em que a escola está inserida para entender qual é a realidade dos alunos que ali estão. Ter a consciência de ensinar conforme orienta a 
pedagogia musical atual e ter muita paciência quanto aos resultados e principalmente com a recusa das turmas.

A música está presente na vida do ser humano desde a sua introdução na terra, e é elemento importante para a formação do individuo dentro de uma sociedade desde a Grécia Antiga. Para os gregos, especialmente Platão, a formação do cidadão era importante não só para si próprio, mas para a pólis e seus interesses em formar uma sociedade ideal.

Para Platão e todos os gregos, a literatura, a música e a arte têm grande influência no caráter, e seu objetivo é imprimir ritmo, harmonia e temperança à alma. Por isso deve-se preserva-la como tarefa do Estado. (FONTERRADA, 2008, p. 27).

Segundo Fonterrada (2008), na Idade Média a música fazia parte do quadrivium, a mais alta divisão das sete artes liberais, compartilhando o seu espaço com a aritmética, a astronomia e a geometria. Já na Idade Moderna a música não era elemento essencial para a arte, uma vez que a poesia estava em mais evidência e era considerada mais importante.

No Brasil, o ensino da música no espaço formal se deu inicialmente com o canto orfeônico de Villa-Lobos no século XX. Com ele, o autor pretendia fazer com que todas as pessoas cantassem, ou seja, que todo brasileiro matriculado na escola pudesse cantar as músicas por meio do Canto Orfeônico.

No âmbito das artes, podemos afirmar que a Indústria Cultural está empenhada a vendê-la, seja na música, nos filmes, nas artes visuais, em novelas, na televisão em geral, nos programas de rádio, em revistas e jornais. $E$ isso se dá com uma pesquisa minimalista que a indústria faz na população para saber o que ela quer consumir. Infelizmente isso afeta a educação musical no âmbito escolar.

A educação musical vai, no espaço escolar, muito além de executar música, ela engloba senso de direcionamento, treinamento auditivo, trabalho em conjunto, criação, composição, reconhecimento de padrões rítmicos e melódicos, reconhecimento de paisagem sonora entre outros. Porém, todos os conteúdos elencados acima têm como principal objetivo refletir sobre a Arte, no caso a música, e o fazer musical. De acordo com os Parâmetros Curriculares Nacionais para o Ensino Médio (2000, p. 50)

Adolescentes, jovens e adultos, na escola média, podem desenvolver competências em Arte, na medida em que praticam modos de fazer produtos artísticos (experimentando elaborações inventivas- percepções e imaginações com significado sobre a cultura -, expressões síntese de sentimentos) e maneiras de fazer apreciações e fruições em cada linguagem da Arte ou em várias possibilidades de articulação. Na medida em que tais fazeres são acompanhados 
de reflexões, troca de ideias, pesquisas e contextualizações históricas e socioculturais sobre essas práticas, transformam conhecimentos estéticos e artísticos anteriores em compreensões mais amplas e em prazer de conviver com a arte.

Já o Currículo nacional do Ensino Básico - competências essenciais prevê que ao final do Ensino Básico o aluno estará apto, entre outros fatores, a compreender "os modos como as sociedades contemporâneas se relacionam com a música" (2011, p.176).

Nesse sentido, faz-se necessário saber que a influência da Indústria Cultural está presente também no comportamento dos alunos, no valor da obra de arte e nas práticas socioculturais. A questão seria então conscientizar os alunos de tal prática e propor, por metodologias que envolvam os alunos, a conscientizar sobre o que é e como funciona a Indústria Cultural a ponto de promover a transformação social.

As reflexões sobre as influências da Indústria Cultural na educação têm permeado as discussões entre os pesquisadores que procuram compreender a mudança de valores e de práticas socioculturais entre os indivíduos, em grande parte promovida pela mídia. Esta mudança de valores também vem ocorrendo nas Artes (dança, música, artes plásticas). (BERTONI, 2001, p. 76)

O ensino de música no espaço formal tornou-se obrigatório no Brasil com a promulgação da Lei n. 11.796/08 dentro do currículo de Artes. Após ela, as escolas tiveram um período de três anos para se adaptarem e inserir a matéria no conteúdo curricular. Porém, o número de licenciados em música não era o suficiente para atender a demanda e professores generalistas se viram obrigados a ensinar o conteúdo de música. Sem o conhecimento específico esses professores encontraram como única solução o uso de músicas oriundas da Indústria Cultural para o seu ensino. Segundo Nogueira (2012), vemos com certa preocupação a veiculação de propostas que têm nos produtos da Indústria Cultural o repertório-base para o trabalho pedagógico-musical nas escolas.

Porém não podemos culpar os professores generalistas por tal fato. É preciso reconhecer que estes não possuem formação adequada para o ensino da música. Sendo assim como seria a maneira correta de ensinar música na escola? A maneira correta é aquela que não está presente em conservatórios e escolas de músicas em nosso país, pois segundo Koellreutter $(1997$, p. 37):

Acontece que os nossos estabelecimentos de ensino musical ainda se orientam pelas normas e pelos critérios em que estavam baseados os programas e currículos dos conservatórios europeus do século passado, revelando-se instituições alheias à realidade social brasileira, na segunda metade do século XX, e servindo, dessa maneira, a interesses que não podem ser os interesses culturais de nosso país. 
Assim, o ensino da música no espaço formal deve ser calcado na experiência e na realidade de cada aluno, na realidade social em que a escola está inserida e na experiência desses alunos com o mundo sonoro. Primeiro é preciso apresentar a paisagem sonora para esses alunos, ensinálos a escutar de forma correta, fazendo com que eles descubram o mundo através dos sons que estão inseridos nele. Antes de levar para a sala de aula as músicas prontas oriundas da Indústria Cultural, antes de fazer a apreciação e análises dessas músicas se faz necessário colocar os alunos para experimentarem uma apreciação e manipulação dos sons do cotidiano.

Com essa maneira de ensino musical, teremos uma resposta positiva na aprendizagem da música, pois com ela criaremos uma intimidade entre alunos e música onde os sons se transformarão em melodia, as melodias em gestos, os gestos em estruturas simbólicas e essas em experiências significativas. De acordo com Swanwick (2003), uma visão de música como uma forma de discurso impregnada de metáfora tem consequências importantes para a educação musical.

\section{DISCUSSÃO}

O assunto escolhido é de grande relevância para a educação musical uma vez que, em dias atuais, nossos educandos consomem de forma demasiada os produtos da Indústria Cultural.

Como dito na introdução, hoje a grande massa consome apenas aquilo que é imposto pela mídia e que a mesma julga ser o padrão de beleza, estética e comportamento. Frente a essa situação como podemos inserir nas escolas uma pedagogia musical que vai contrária ao objetivo da Indústria Cultural? Como dizer ao aluno que somente tem contato com os produtos dessa indústria que o mundo das artes é algo bem amplo e cheio de possibilidades? Esse é o grande desafio da educação musical atual e também uma possibilidade de discutir e proporcionar aos estudantes uma emancipação cultural.

\section{CONCLUSÃO}

Em algumas escolas visitadas para observação como requisito da disciplina de Estágio Supervisionado do curso de graduação em música, foi possível verificar que a realidade musical dos alunos está calcada em dois estilos: o dito sertanejo universitário e o funk carioca. Ao questionar os alunos o porquê de somente escutarem esses dois tipos de música a resposta foi unânime: "Porque é top!", e o que é ser top? Para eles, "top" é ser e agir conforme os artistas que estão em evidência na mídia. 
Com isso o trabalho de educação musical pode ser árduo e de longo prazo, mas a influência da Indústria Cultural não pode ser empecilho para nós educadores musical, pelo contrário, devemos usá-la a nosso favor uma vez que a sua influência é grande na vida dos jovens educandos de nosso país. E como usar as músicas de massa a favor da educação musical?

É possível educar musicalmente dentro das escolas que consomem os produtos da Indústria Cultural de maneira massiva. É possível ensinar percepção com as músicas de massa, basta fazer um comparativo entre essa música e uma música clássica, uma música eletroacústica, uma música modal e uma música contemporânea. É possível trazer os alunos ao mundo dos ambientes sonoros com trabalhos de paisagem sonora, de captação e manipulação de ruídos e de sons com altura definida. Basta ter muita paciência e muita força de vontade em educar.

\section{REFERÊNCIAS}

ADORNO, T. W. Indústria cultural e sociedade. 7 ed. São Paulo: Editora Paz e Terra, 2002.

BERTONI, L. M. Arte, indústria cultural e educação. 21 ed. Araraquara: Editora Unesp, 2001.

BRASIL/MEC. PARÂMETROS CURRICULARES NACIONAIS (Ensino Médio). 2000.

BRASIL/ MEC. Currículo Nacional do Ensino Básico - Competências Essenciais. Despacho n $17169 / 2011$.

DUARTE, R. Teoria crítica da indústria cultural. 109 ed. Belo Horizonte: Editora UFMG, 2003.

FONTERRADA, M. De tramas e fios. Um ensaio sobre música e educação. 2 ed. São Paulo: Editora Unesp; Rio de Janeiro: Funarte, 2008.

KOELLREUTTER, H. J. Cadernos de estudo: educação musical organização Carlos Kater. 1 ed. Belo Horizonte: Atravéz EMUFMG, 1997.

NOGUEIRA, M. A. Educação musical no contexto da indústria cultural: alguns fundamentos para a formação do pedagogo. Educação, Santa Maria. V.37, n. 3, p.615-626. Rio de Janeiro: Editora UFRJ, 2012.

SWANWICK, K. Ensinando música musicalmente. Tradução Alda Oliveira e Cristina Tourinho. 1 ed. São Paulo: Editora Moderna, 2003. 